\title{
Descrição de possíveis microRNAs envolvidos na imunopatogênese do vírus Zika relacionados a microcefalia
}

\section{Description Of Possible MicroRNAs Involved In The Immunopathogenesis Of The Zika Virus Related To Microcephaly}

Karla Fabiane Lopes de Melo ${ }^{1,4}$, Francisco Canindé Ferreira de Luna², Lucas dos Santos Pamponet $^{3}$, Fernanda Rodrigues Dias ${ }^{3}$, Maria Clara Valente de Freitas ${ }^{4}$, Edna Cristina Franco ${ }^{1}$, Samir Mansour Moraes Casseb ${ }^{1,2 *}$

\section{RESUMO}

O vírus Zika (VZIK) é um flavivírus da família Flaviviridae, que apresenta um genoma composto por RNA fita simples de polaridade positiva, não segmentado, que codifica uma grande poliproteína precursora que é clivada originando três proteínas estruturais e sete proteínas não estruturais. Apresentando a capacidade de infectar células progenitoras neurais, a microcefalia é a mais grave e irreversível complicação neurológica associada ao VZIK, causando desenvolvimento inadequado e/ou destruição de células neurais, processo que pode estar relacionado a alterações do perfil de expressão dos microRNAs (miRNAs) do hospedeiro. Os miRNAs são pequenas moléculas de RNA não codificadores de proteínas, que apresentam importância em diversos processos biológicos, como no desenvolvimento embrionário, estando envolvidos na regulação gênica de células-tronco embrionárias e em processos relacionados à neurogênese. Trata-se de uma revisão de literatura a partir da bibliografia disponível a respeito do vírus Zika, onde 25 artigos foram qualificados para agregar os resultados. Os miRNAs estudados, miR-9, miR-124, miR-128, miR-1792, Let-7, miR-302, miR-290, miR-155 e miR-146, demonstram ter significativa importância nos processos envolvendo a imunopatogênese do VZIK em casos de microcefalia, estando incluídos em processos relacionados a determinação de linhagens neurais, ativação e regulação do sistema imune, proliferação e diferenciação celular durante desenvolvimento embrionário.

Palavras-chave: Vírus Zika; miRNA e Vírus; Patogênese dos Flavivírus; Microcefalia e VZIK.

\section{ABSTRACT}

The Zika virus (ZIKV) is a flavivirus of the flaviviridae family, which presents a genome composed of simple non-segmented polarity positive, single strand RNA that encodes a large precursor polyprotein that is cleaved giving rise to three structural proteins and seven non-structural proteins. Microcephaly is the most serious and irreversible neurological complication associated with VZIK, causing inadequate development and/or destruction of neural cells, a process that may be related to changes in the expression profile of microRNAs (miRNAs) of the host. The miRNAs are small molecules of non-protein-coding

\footnotetext{
${ }^{1}$ Instituto Evandro Chagas, Ananindeua, Pará, Brasil

${ }^{2}$ Universidade Federal do Pará, Belém, Pará, Brasil

${ }^{3}$ Escola Superior da Amazônia, Belém, Pará, Brasil

${ }^{4}$ Escola Superior Madre Celeste, Ananindeua, Pará, Brasil

* E-mail: samir.casseb@gmail.com
} 
RNA, which are important in several biological processes, such as embryonic development, being involved in the regulation of embryonic stem cells and in processes related to neurogenesis. This is a literature review from the available literature on the Zika virus, where 25 articles were qualified to aggregate the results. The miRNAs studied, miR-9, miR-124, miR-128, miR-17-92, Let-7, miR-302, miR-290, miR-155 and miR146 , immunopathogenesis of VZIK in cases of microcephaly, being included in processes related to the determination of neural lines, activation and regulation of the immune system, and cell proliferation and differentiation during embryonic development.

Keywords: Zika virus; miRNA and viruses; Pathogenesis of Flaviviruses; Microcephaly and VZIK.

\section{INTRODUÇÃO}

O vírus Zika (VZIK) é um arbovírus pertencente à família Flaviviridae e do gênero Flavivirus, família está composta por mais de 40 agentes patogênicos ao homem de importância mundial, como o vírus da Dengue e o vírus do Nilo Ocidental. Sua transmissão se dá através da picada do mosquito fêmea do gênero Aedes e, em menor número, por via sexual, perinatal e por hemotransfusão. Sua descoberta se deu em 1947 em macaco Rhesus, na Floresta Zika, em Uganda, através de um monitoramento de febre amarela. Anos depois, em 1952, foram detectados os primeiros casos do vírus em humanos, seguidos de casos em países da África e sudoeste da Ásia e, posteriormente sendo descritos três surtos: na Ilha de Yap, na Micronésia em 2007; na Polinésia Francesa entre 2013 e 2014; e no Brasil em 2015. Sugere-se que o vírus tenha entrado no país por meio de eventos esportivos de cunho internacional, como a Copa do Mundo da FIFA, de 2014 (SIVA, 2017).

O VZIK tem seu genoma composto por RNA fita simples, polaridade positiva e não segmentado, com um comprimento médio de 10,8 Kb, apresentando um capsídeo de simetria icosaédrica, envolto por um invólucro lipídico que limita o nucleocapsídeo composto pela proteína $\mathrm{C}$ do capsídeo e o genoma viral. Este invólucro deverá conter as proteínas de superfície M (glicoproteína de membrana) e E (proteína de envelope). Essas três proteínas estruturais são essenciais para a formação da forma infecciosa do vírus, com as partículas virais medindo cerca de 40-60 nm de diâmetro. Além disso, seu genoma consiste em uma única cadeia aberta de leitura, que é flanqueada por duas regiões 5' e 3' não codificantes, na qual codifica uma poliproteína de 3423 aminoácidos, que é clivada originando três proteínas estruturais $(\mathrm{C}, \mathrm{M}$ e E) e sete proteínas não estruturais - NS1, NS2A, NS2B, NS3, NS4A, NS4B e NS5 -, responsáveis por atividades regulatórias e de 
expressão viral, como replicação, virulência e patogenicidade (SILVA, 2017; SONG, 2017).

Sabe-se que o VZIK tem tropismo por células progenitoras neurais (NPCs), astrócitos, algumas células do trato genital masculino e feminino, células de Hofbauer, trofoblastos placentários, além de infectar tecidos oculares. Pela variedade de células infectadas, é possível encontrar o vírus em diversos fluidos corporais incluindo saliva, sêmen, urina e tecido conjuntivo (MINER; DIAMOND, 2017). A possível associação com a Microcefalia e o VZIK se deu em 2015 em Pernambuco, Brasil, quando o número de recém-nascidos diagnosticados com microcefalia aumentou, seguido de mesmo relato na Paraíba e no Rio Grande do Norte, episódio já relatado no surto do vírus na Polinésia Francesa. Caracterizada como uma doença neurológica rara, a microcefalia se caracteriza pelo Perímetro Cefálico (PC) ser menor que dois desvios-padrão (31 centímetros) ou mais, associado a outras crianças de mesma faixa etária e sexo (KOZAK, 2017).

Geralmente causada por um desenvolvimento inadequado e/ou destruição de células neurais, a microcefalia apresenta várias causas, podendo ocorrer durante o período intrauterino ou após o nascimento (SIVA, 2017).

Os flavivírus moderam a expressão gênica para neutralizar as respostas ao vírus ou manter um ambiente que seja favorável à replicação, processo este que pode envolver a alteração do perfil dos miRNAs do hospedeiro (KOZAK, 2017).

Os miRNAs são pequenos RNAs, de cerca de 20 nucleotídeos, não codificadores de proteínas, que se ligam a sequências complementares de RNAs mensageiros (mRNAs) para reprimir a tradução ou clivagem desses RNAs e fazer a manutenção do genoma, regulando diversos processos celulares como proliferação, diferenciação e morte celular (COSTA e PACHECO, 2012).

A importância no desenvolvimento embrionário, pois mantém o estado pluripotente de células-tronco embrionárias (ESCs), regulam a expressão gênica dessas células e participam em processos de neurogênese, (COSTA e PACHECO, 2012; CAMPOS, 2011) sendo regulados precisamente no desenvolvimento do cérebro de mamíferos. Durante a diferenciação de células progenitoras neurais, a variação da expressão destes miRNAs pode gerar redução no número de astrócitos ou de neurônios formados (KRICHEVSKY, 2006).

Além disso, os miRNAs participam da interação entre vírus e célula hospedeira e regulam infecções virais. Alguns vírus podem codificá-los e utilizá-los para regular a 
expressão das proteínas virais e facilitar a replicação viral em células hospedeiras impedindo a resposta antiviral (SULLIVAN e GANDEN, 2005).

miRNAs expressos no tecido cerebral podem controlar o neurotropismo de flavivírus causadores de desordens neurológicas a partir do reconhecimento de sequências complementares, o que impediria a replicação e montagem de uma nova partícula viral (HEISS; MAXIMOVA; PLETNEV, 2011).

Assim, o objetivo deste trabalho foi, através de levantamento bibliográfico, descrever a expressão dos miRNAs envolvidos na regulação da infecção viral e regulação da resposta imunológica ao VZIK para auxiliar na elucidação do mecanismo da infecção perinatal através da desregulação dos miRNAs em casos de microcefalia.

\section{MATERIAIS E MÉTODOS}

Trata-se de um estudo caracterizado como uma revisão de literatura a partir da bibliografia disponível a respeito do VZIK, sendo um estudo do tipo descritivo. Como objetos de estudo, serão analisados artigos, livros, monografias, dissertações e teses de domínio público, entre os anos de 2005 e 2018, considerando a qualidade e a significância do conteúdo para a elaboração desta revisão, incluindo artigos originais, relatos de casos e revisões de literatura. Os bancos de dados utilizados foram SciELO, ScienceDirect, PubMed, Medline, Periódicos Capes, Biblioteca Virtual em Saúde e Google, considerando publicações nas línguas português brasileiro e inglês. A busca foi executada utilizando as seguintes palavras-chave: "Vírus Zika", "microRNAs and virus", "miRNA e vírus", "Patogênese dos Flavivírus", "Apoptose viral", "Microcefalia e VZIK" e "Neurogenesis and virus".

A escolha do material para compor os resultados desta revisão foi realizada através da leitura superficial dos trabalhos (leitura e análise dos títulos e resumos com o intuito de verificar a relevância do material). Desta forma, 116 artigos foram encontrados na pesquisa, mas somente 30 foram qualificados para agregar os resultados. A partir da leitura analítica do material, realizada com o objetivo de reunir as informações comuns aos diferentes autores, foram elaboradas tabelas e gráficos, para a tabulação dos dados, no programa Microsoft Excel (Pacote Office 2010).

\section{RESULTADOS}


A quadro 1 identifica os principais microRNAs encontrados para compor os resultados, seguidos da espécie onde estão presentes e suas funções conforme os trabalhos pesquisados.

Quadro 1 - Principais microRNAs encontrados nos trabalhos científicos pesquisados.

\begin{tabular}{|c|c|c|}
\hline microRNA & Espécie & Função \\
\hline $\operatorname{miR}-9$ & $\begin{array}{l}\text { Mus musculus e Homo } \\
\text { sapiens }\end{array}$ & $\begin{array}{c}\text { Determinar linhagens neurais } \\
\text { derivadas de células-tronco } \\
\text { embrionárias (ESC) }\end{array}$ \\
\hline miR-124 & $\begin{array}{l}\text { Mus musculus e Homo } \\
\text { sapiens }\end{array}$ & $\begin{array}{c}\text { Determinar linhagens neurais } \\
\text { derivadas de ESCs }\end{array}$ \\
\hline miR-128 & $\begin{array}{l}\text { Mus musculus e Homo } \\
\text { sapiens }\end{array}$ & $\begin{array}{c}\text { Determinar linhagens neurais } \\
\text { derivadas de ESCs }\end{array}$ \\
\hline $\begin{array}{l}\text { miR-17-92 } \\
\text { (Família) }\end{array}$ & Rattus rattus & $\begin{array}{c}\text { Proliferação e diferenciação celular } \\
\text { durante desenvolvimento } \\
\text { embrionário }\end{array}$ \\
\hline Let-7 (Família) & Homo sapiens & $\begin{array}{c}\text { Proliferação e diferenciação celular } \\
\text { durante desenvolvimento } \\
\text { embrionário }\end{array}$ \\
\hline miR-302 & $\begin{array}{l}\text { Mus musculus e Homo } \\
\text { sapiens }\end{array}$ & $\begin{array}{c}\text { Regula positivamente a pluripotência } \\
\text { de ESCs }\end{array}$ \\
\hline miR-290 (Família) & Mus musculus & $\begin{array}{c}\text { Regulação da pluripotência em } \\
\text { ESCs }\end{array}$ \\
\hline miR-155 & Murinae e Homo sapiens & $\begin{array}{c}\text { Ativação e regulação do sistema } \\
\text { imune }\end{array}$ \\
\hline miR-146a/b & Murinae e Homo sapiens & Regulador da resposta imune \\
\hline
\end{tabular}

Fonte: Próprio autor

É possível observar que os miR-9 e o miR-124 são referidos em treze e catorze materiais, respectivamente, de um total de 25 artigos, enquanto o miR-128 está presente em apenas quatro artigos; por conseguinte, a família miR-290 e miR-17-92, assim como, o miR-302, o miR-155 e o miR-146a/b destacam-se em cinco estudos; a família de miRNA Let-7 é citada em oito trabalhos científicos (Figura 1). 
Figura 1 - Distribuição dos principais miRNAs conforme a frequência de citações em diferentes estudos.

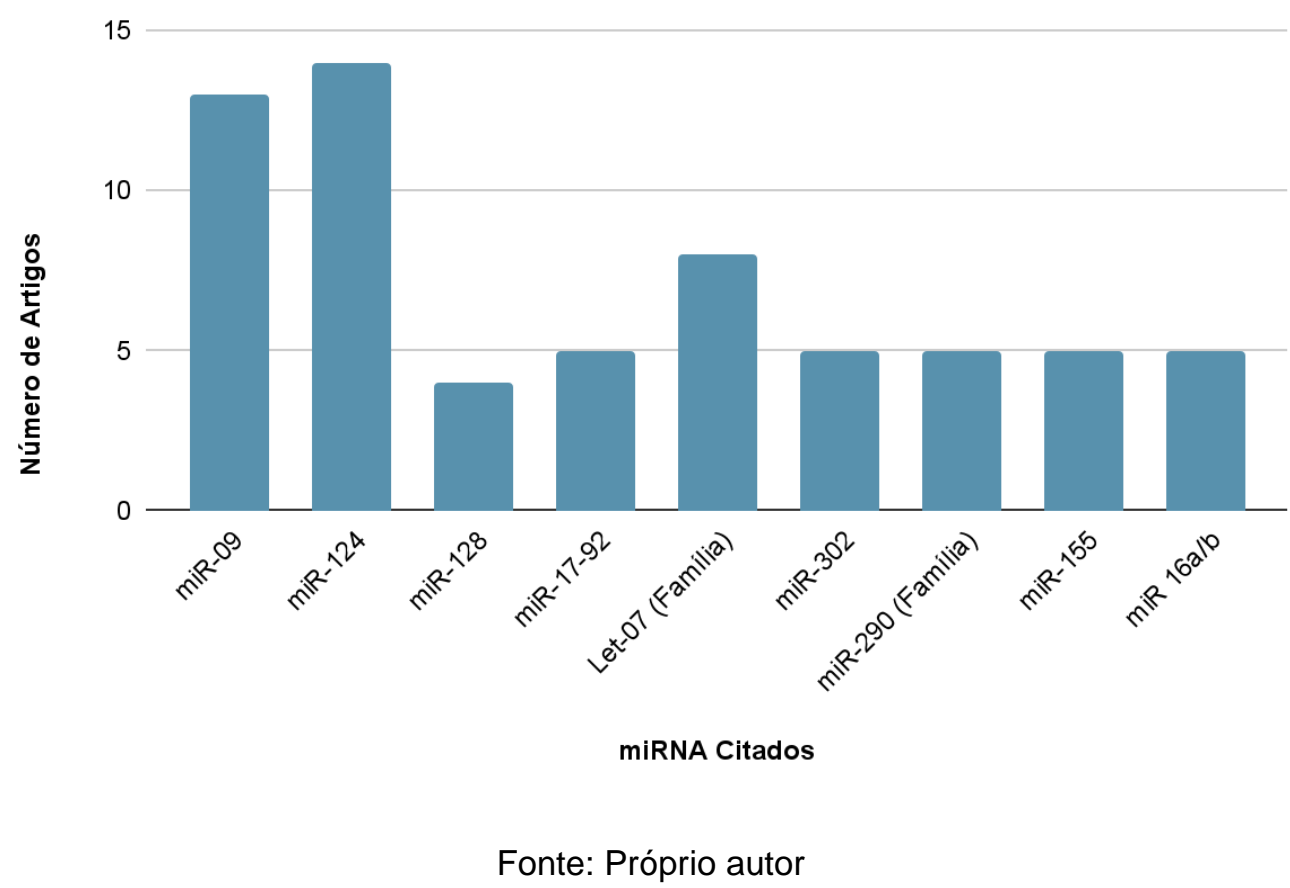

\section{DISCUSSÃO}

Existem ao menos 400 miRNAs expressos em humanos, muitos deles expressos no cérebro, com funções específicas ou mesmo distintas em diferentes estágios do desenvolvimento, portanto, a utilização destes miRNAs por um vírus neurotrópico, como VZIK, para facilitar a sua replicação e patogênese não é surpreendente.

Sabe-se que estes pequenos RNAs apresentam diversas funções importantes no desenvolvimento embrionário, seja na neurogênese, através do seu funcionamento e morfogênese em vermes e peixes, a gliogênese e participação em acontecimentos que levam a determinação de linhagens neurais derivadas de (ESCs) em mamíferos, como é citado por Costa e Pacheco (2012).

Ainda neste estudo Costa e Pacheco (2012) observam que os miR-9 e miR-124a, miRNAs cérebros específicos, atuam e eventos importantes na neurogênese e diferenciação de células-tronco embrionárias neurais e neurogliais em camundongos.

Li et al (2009) descrevem os miRNAs da família let-7 são importantes na ativação, manutenção da pluripotência de células-tronco e regulação da neurogênese de ESCs em células-tronco pluripotente induzidas (iPSCs). Induzindo genes de diferenciação neural, 
desta forma demonstrando que a supressão do miR-371-3, altamente expresso em iPSCs e ESCs em humanos, consegue promover a diferenciação neural.

Além disso, os miR-9 e miR-124 são promotores da diferenciação de células neurais da zona subventricular e de células-tronco da linhagem neural, respectivamente, vale salientar o papel fundamental do miR-124 na diferenciação de células progenitoras para neurônios maduros (MAKEYEV et al, 2007).

Na diferenciação neural de ESCs humanas, o miR-9 tem sua expressão ativada em células progenitoras neurais humanas e mantida em neurônios pós-mitóticos, onde Delaloy et al (2010) demonstraram uma nova função autônoma de células para o miR-9 na regulação do comportamento migratório de NPCs humanas, identificando este miRNA como um novo regulador que é capaz de coordenar a proliferação e migração de NPCs humanas.

Visvanathan et al (2007) descrevem o papel do miRNA miR-124 na neurogênese, através de um estudo que demonstra sua relação antagônica com o REST/SCP1, onde no desenvolvimento da medula espinhal de um pinto em desenvolvimento. A expressão de miR-124 e SCP1 seria complementar, e seu antagonismo causaria a superexpressão de SCP1 e vice-versa.

Nas células P19, o miR-124 suprime a expressão do SCP1 e induz a neurogênese, e o SCP1 neutraliza essa atividade pró-neural do miR-124. Esses dados sugerem que o miR-124 superexpresso atenua a proliferação de progenitores neurais e promove sua neurogênese precoce (VISVANATHAN et al, 2007).

A superexpressão do miR-9 e miR-124, específicos do sistema nervoso central, em precursores neurais ocasiona a redução do número de astrócitos, importantes células do sistema nervoso responsáveis por sustentar e nutrir os neurônios, fundamentais em diversas atividades cerebrais, como evidenciam Campos et al (2011) além do let-7.

Enquanto o Knockdown (redução) de miR-9 e miR-124, levam a uma redução na formação de neurônios, o miR-124 ligando-se a região 3'UTR do transcrito do gene SCPI e reprimindo sua tradução, consequentemente reduzindo a tradução de SCPI que induz a neurogênese em galinhas e camundongos (CAMPOS et al, 2011). Estudos de Shim e Nam (2016) descrevem que a expressão de miR-124 e miR-128 leva à indução da diferenciação de células neuronais, onde a relação do miR-124 com SCP1 levaria à diferenciação de astrócitos. 
Krichevsky et al (2006) demonstraram que a superexpressão precoce do miR-124a em precursores neurais previne a gliogênese, assim com a expressão de miR-9 contribui para a neurogênese, notando-se que a superexpressão ou inibição desses miRNAs pode afetar outras células, ou fatores nas culturas de diferenciação.

Estudos de Liu e Zhao (2009) esclarecem que a superexpressão do miR-9 e do miR-124 promove a diferenciação neural. Assim como sua regulação negativa apresenta o efeito oposto, além da expressão do miRNA let-7 ser induzida durante o desenvolvimento embrionário isto regula negativamente a auto-renovação de célulastronco em uma variedade de tecidos.

Os miRNAs miR-9 e miR124, são altamente específicos e expressos em diversas regiões do SNC. Funcionam como mediadores da neurogênese, sugerindo que eles atuem, pelo menos parcialmente, ao nível da tradução, além dos resultados do estudo implicarem que ambos atuem na via de sinalização da STAT3, afetando diferenciação de astrócitos em desenvolvimento e suprime a neurogênese das células-tronco neurais (KRICHEVSKY et al, 2006).

Yoo et al (2009) também salientam a importância do miR-9 e do miR-124 na proliferação e diferenciação de células da linhagem neural, demonstrando através de um estudo que o momento da saída mitótica, quando as células perdem a multivariação e começam a desenvolver conexões estáveis, é mediado pela repressão da BAF53a através do miR-9 e do miR-124. Sendo a BAF53a uma subunidade do complexo npBAF, essenciais para a proliferação de células progenitoras neurais e, em camundongos que apresentam dosagem reduzida para os genes que codificam suas subunidades, manifestam defeitos no fechamento do tubo neural, um dos mais graves defeitos congênitos.

Em camundongos, a família de miRNAs maternos mais abundantes são os do let7, (CAMPOS et al, 2011) que desempenham diversas funções biológicas, como a proliferação e diferenciação celular durante desenvolvimento embrionário como é mencionado no estudo de Rosa e Brivanlou (ROSA e BRIVANLOU, 2013).

Zhao et al (2013), como o let-7a que pode regular a diferenciação de precursores neurais, assim como o let-7b pode regular negativamente a autorrenovação de célulastronco neurais. Além disso, demonstram também que o let-7d pode regular múltiplos aspectos da neurogênese, incluindo a proliferação de células-tronco neurais, a diferenciação e a migração neuronal no cérebro de mamíferos. 
A superexpressão de let-7d inibe a proliferação de células-tronco neurais e, ao contrário, promove a diferenciação neuronal e a migração para o exterior. Além disso, o let-7d regulou estes efeitos na neurogênese modulando a cascata de expressão de TLX e miR-9, mostrando que quando o let-7d está superexpresso, a expressão de TLX era inibida, o que induzia a expressão de miR-9 (ZHAO et al, 2013).

Kawahara, Imai e Okano (2012) também salientam a importância dos miRNAs-9, miR-124 e do let-7 na proliferação de células-tronco e em processos relacionados à neurogênese.

Heiss, Maximova e Pletnev (2011) elaboraram um estudo onde, através da incorporação no genoma viral de uma sequência alvo para miRNAs celulares expressos no sistema nervoso, permitiu a alteração do fenótipo do flavivírus neurotrópicos e o controle da neuropatogênese, comprovando que certos miRNAs conseguem controlar o neurotropismo de flavivírus causadores de desordens neurológicas. Para isso utilizaram o vírus da Dengue (TBEV/VDEN4) como modelo para a modificação, onde a inclusão de apenas uma cópia-alvo de miR-9, miR-124a, miR-128a, miR-218 ou let-7 no genoma do vírus molde, se mostrou suficiente para prevenir o desenvolvimento de formas letais de encefalites em camundongos infectados com uma grande dose do vírus.

Considerando que os miRNAs let-7 e miR-124a altamente expressos em diversas regiões do SNC, o vírus contendo suas sequências alvo teve sua patogenicidade reduzida, restringindo a neurovirulência e neuro invasividade in vivo, além disso, embora a inclusão de sequências alvo para outros três miRNAs expressos no SNC (miR-9, miR-128a e miR218) tenham abolido completamente a neurovirulência do vírus TBEV/VDEN4 em camundongos imunocompetentes, efeito equivalente para a sequência utilizando o miR124a, o efeito dessas inserções de miRNA no alvo do fenótipo neuro invasivo viral em camundongos imunodeficientes foi menos evidente do que o de uma inserção de alvo let7c ou miR-124a.

Mesmo os miRNAs, miR-128 e miR-128a, apresentando menor eficiência no controle da patogenicidade de flavivírus causadores de desordens neurológicas, o que pode ser explicado pela expressão limitada a certas regiões do cérebro, o importante papel do nível de expressão dos miRNAs citados anteriormente, com o miR-9, miR-124a e let7, no controle da replicação viral dentro do SNC não deve ser subestimado. Assim como Nelson, Wang e Rajeev,(2008) que citam o miR-128 em seu estudo que relaciona os miRNAs nas doenças neurodegenerativas. 
Teterina et al (2014) obtiveram respostas semelhantes através de um estudo similar utilizando como sequências alvo os miRNAs miR-124a e miR-9 para o vírus TBEV/VDEN4, onde o miR-124a também se mostrou eficaz para a atenuação da neuropatogenicidade, sobretudo em relação à replicação do vírus em células neuronais primárias e neurovirulência em camundongos neonatais. Enquanto, com a substituição da sequência alvo do miR-124a para o miR-9, os efeitos de atenuação foram reduzidos tanto in vivo quanto in vitro.

Estudo destacando os potenciais miRNAs que podem ser importantes na patogênese do VZIK, Kozak et al (2017) avaliou a replicação viral na linhagem de astrócitos fetais humanos (SGV-A) observando um aumento na morte celular a medida que a infecção progrediu. Suas descobertas sugerem que o vírus induz, em geral, uma supressão global de miRNAs, onde os com maior indução durante o curso da infecção foram miRNA-9-5p, miR-17-5p, miR-146b-5p e miR-30- 3p, indicando que a infecção pelo VZIK altera a expressão de miRNAs. Vários miRNAs estão relacionados a várias vias hospedeiras envolvidas na infecção pelo VZIK, além de terem sido identificados na patogênese de outros flavivírus. Além de vários genes envolvidos no metabolismo do RNA também terem sido desregulados, como o Dicer1, essencial para a via de interferência de RNA, o que pode ter contribuído para a redução de miRNAs.

Os miRNAs também exercem importantes funções como reguladores da pluripotência das células-tronco, visto que, quando Dicer ou DGCR8, importantes enzimas na biogênese dos miRNAs, sofrem algum tipo de mutação que resulte em funções defeituosas, a diferenciação das ESCs é abalada (LI et al, 2017).

Li et al (2017), relata também que a família miR-290 pode afetar o estado de pluripotência e diferenciação das ESCs e a família miR-17-92, assim como o miR-302 são importantes para a ativação e manutenção do estado pluripotente dessas células. Além disso, muitos miRNAs, como o miR-17, o miR-290 e o miR-302, estão envolvidos no processo de reprogramação celular através da regulação dos fatores do ciclo celular, podendo aumentar a eficiência da reprogramação (LI et al, 2017; ROSA e BRIVANLOU, 2013).

Em seu trabalho, Rosa e Brivanlou (2013) afirmam que, dos miRNAs específicos para ESCs, a família miR-302 e miR-290 são as que se destacam por serem altamente expressas e regularem a pluripotência e diferenciação dessas células. No entanto, assim como Rosa e Brivanlou (2013), Tiscornia e Belmonte (2010) mostram que essas famílias, 
com a família miR-17-92 são superexpressas em ESCs indiferenciadas, porém sofrem declínio com a diferenciação celular, ao contrário do que ocorre com a família do miRNA let-7, que está ausente em ESCs indiferenciadas e após a diferenciação destas, sofre um acúmulo, mostrando-se altamente expressa em tipos diferenciados.

Além disso, Rosa e Brivanlou (2013) demonstram que a família miR-302 está envolvida na regulação negativa da indução neural em ESCs e que o fator de transcrição, NR2F2 é importante para a expressão adequada dos genes do SNC e regulam a saída das células-tronco embrionárias humanas da pluripotência para um destino neural. Identificou-se, também, como um repressor transcricional de metiltransferase de DNA e alvo da família miR-290, o Rbl2, que supra-regulado, na ausência do miR-290, resulta na deficiência celular para silenciar os marcadores de pluripotência, explicando, assim, os defeitos de diferenciação observados nas células Dicer - / - (ROSA e BRIVANLOU, 2013; TISCORNIA e BELMONTE, 2010).

Para Shim e Nam (2016), a regulação positiva da família miR-302 induziu a autorrenovação de ECSs humanas e bloqueou a apoptose pela regulação negativa de BNIP3L / Nix. Além disso, este autor mostrou, assim como Rosa e Brivanlou (2013) que a família miR-302 pode suprimir a diferenciação neural das células-tronco embrionárias humanas quando sua expressão é mantida, sugerindo que quando há baixa expressão desta família de miRNA, a diferenciação neural pode ser induzida.

Yuan et al (2017) também relatam que a família miR-290 sofre uma supraregulação durante a diferenciação celular e que mantém a pluripotência das ESCs, estando, nessa fase, superexpressa. Entretanto, Gu et al (2016) afirma que as famílias miR-290 e miR-17-92 permaneceram em níveis similares do início ao término da diferenciação e que somente o miR-302 é supra-regulado logo no início da diferenciação celular. Yuan et al (2017), em concordância com Gu et al (2016) evidenciam que tanto a família miR-290 quanto miR-302 podem promover a transição da pluripotência naïve para primed, ou diferenciada.

Kosak et al (2017) revelam que membros da família miR-17-92, como o miR-19b, têm sua expressão aumentada em células astrogliais humanas quando há infecção pelo vírus da encefalite japonesa (VEJ). Este estudo também mostra que o miR-17-5p é um dos principais miRNAs regulados na replicação de flavivírus e foi um dos que apresentaram maior indução durante o curso da infecção, assim como o miR-146b. 
Ainda como afirmam Kosak et al (2017), a família miR-17-92 é altamente expressa em células germinativas primordiais de camundongos e atuam na regulação de células pluripotentes em mamíferos. Este grupo de miRNAs também pode estar associado à resposta imune, onde sua superexpressão pode levar a morte prematura por autoimunidade, da mesma forma que a ausência de expressão leva ao aumento nos níveis de Bim, um membro pró-apoptótico da família Bcl-2 (LI et al, 2017).

Levando-se em consideração a alta capacidade de diferenciação das ESCs e o importante papel dos miRNAs na regulação desta função, sugere-se que esse mecanismo está envolvido em diversas doenças neurodegenerativas, tais como a microcefalia, e compreender as funções reguladoras dos miRNAs pode ser o primeiro passo para a elucidação da patogênese do VZIK.

Os miRNAs também desempenham um importante papel na regulação do sistema imunológico, pois influenciam várias vias de resposta e estão envolvidos na manutenção das funções efetoras dos linfócitos e modulação da sensibilidade das células T. Li et al (2009) relatam que o miR-155 possui um papel extremamente importante na diferenciação de linfócitos, principalmente o $\mathrm{T}$ helper, e na ativação de anticorpos dependentes de células $\mathrm{T}$.

Os estudos de Li et al (2009), relatam a expressão deste miRNA na linhagem hematopoiética, onde está envolvido na diferenciação das células progenitoras do sistema imune (linhagens linfoide e mieloide) (CULLEN, 2011).

Costa e Pacheco (2012) também evidenciam as funções do miR-146 no sistema imunológico como um importante regulador da resposta contra vírus e diferenciação de células $\mathrm{T}$, assim como a ativação do NF- $\kappa \beta$.

Holanda (2017) afirma que ativação do miR-155 induz a ativação das vias de inteferon do tipo I (IFN-I) para suprimir a replicação viral. Além disso, Holanda (2017) e Li et al (2009) sugerem, assim como Costa e Pacheco (2012), que este miRNA é de extrema importância para a ativação da resposta imune por linfócitos $\mathrm{T}$ e $\mathrm{B}$ e que a deficiência na expressão dele prejudica as funções dessas células, tal como das células dendríticas, e a diferenciação dos linfócitos T naïves em T auxiliares (Th).

O miR-155 também está envolvido na resposta imune inata, sendo altamente expresso em monócitos e macrófagos, principalmente após estímulos inflamatórios. A superexpressão deste miRNA, possibilitou o aumento na produção de TNF- $\alpha$, ( LI et al, 2009). Além disso, no estudo de Bavia et al (2016), é relatado o papel do miR-155 como 
regulador da resposta inflamatória à infecção pelo VEJ, onde foi observada a superexpressão deste no cérebro e em células microgliais primárias de camundongos infectados, assim Bavia et al (2016) concluíram que a infecção por VEJ levou à regulação positiva do miR-155 e aqueles camundongos que tiveram a expressão deste miRNA inibida sofreram redução na síntese de IFN- $\beta$, TNF- $\alpha$ e IL-6. Também identificou o miR115 como um inibidor da replicação viral e de células da microglia, onde, no início da infecção, teve uma regulação negativa. Porém quando o miR-155 foi superexpresso em células microgliais humanas, as proteínas NS1 e o RNA viral foram drasticamente reduzidos, assim como o IFN- $\beta$, IRF-8 (fator de regulação de interferons 8 ) e baixa ativação de NF- $\kappa \beta$.

Bavia et al (2016) revelaram que o miR-146 também está envolvido na regulação da resposta imune inata, atuando como um regulador negativo de IRAK1 e TRAF6, componentes do NF- $\kappa \beta$. Além disso, teve como alvo o STAT1, um transdutor de sinal e ativador de transcrição, importante na ativação da via do IFN-I. O aumento na expressão deste miRNA também revelou a regulação negativa de quimiocinas pró-inflamatórias. (LI et al, 2009) De acordo com Oliveira, (2016) o miR-146 também é um importante regulador de interferon e sua regulação positiva pode estar associada ao aumento da replicação de vírus da hepatite $\mathrm{C}$ (VHC), VEJ, e relacionado com a patogenia do VDEN no fígado por meio da regulação da expressão de citocinas inflamatórias.

\section{CONCLUSÃO}

Os miRNAs desempenham funções abrangentes e específicas no organismo, e dentre eles, o miR-9, miR-124, miR-128, miR-17-92, let-7, miR-302, miR-290, miR-155 e miR-146, demonstram ter significativa importância nos processos envolvendo a imunopatogênese do VZIK em casos de microcefalia, estando incluídos em processos relacionados a determinação de linhagens neurais, ativação e regulação do sistema imune, proliferação e diferenciação celular durante desenvolvimento embrionário. Um dos principais desafios a serem vencidos e elucidados dos mecanismos patológicos envolvidos na infecção pelo VZIK, são necessários estudos adicionais para esclarecer o papel e a influência que os miRNAs podem desempenhar na infecção deste flavivírus. 


\section{REFERÊNCIAS}

BAVIA, L. et al. A glanceat subgenomic flavivirus RNAs and microRNAs in flavivirus infections. Virology Journal, Paraná, v. 13, n. 84, 28 maio 2016, p. 1-20. Disponível em: $<$

https://www.ncbi.nlm.nih.gov/pmc/articles/PMC4884392/pdf/12985_2016_Article_541 .pdf.>. Acesso em: 25 ago. 2021.

CAMPOS, V. F. et al. MicroRNAs e seu papel no desenvolvimento embrionário. Ciência Rural [online]. Rio Grande do Sul, v. 41, n. 1, p. 85-93, jan. 2011. Disponível em: < http://www.scielo.br/pdf/cr/v41n1/a818cr3803.pdf >. Acesso em: 24 ago. 2021.

COSTA, E. de B. O., PACHECO, C. Micro-RNAs: Perspectivas atuais da regulação da expressão gênica em eucariotos. Biosaúde. Londrina, v. 14, n. 2, p. 81-93, 2012. Disponível em:

http://www.uel.br/revistas/uel/index.php/biosaude/article/view/24333/17920>. Acesso em: 25 ago. 2021.

CULLEN, B. R. Viruses and microRNAs: RISCy interactions with serious Consequences. Genes \& Development. 2011, v. 25, p. 1881-1894. Disponível em: <https://www.ncbi.nlm.nih.gov/pmc/articles/PMC3185961/pdf/1881.pdf>. Acesso em: 24 ago. 2021.

DELALOY, C., MicroRNA-9 Coordinates Proliferation and Migration of Human Embryonic Stem Cell-Derived Neural Progenitors. Cell Stem Cell. 2 abr. 2010, v. 6, n. 4, p. 323-335. Disponível em: <https://www.ncbi.nlm.nih.gov/pmc/articles/PMC2851637/pdf/nihms 184598.pdf>. Acesso em: 26 ago. 2021.

GU, K. et al. Pluripotency-associated miR-290/302 family of microRNAs promote the dismantling of naive pluripotency. Cell Research. 2016, v. 26, p. 350-366. Disponível em: <https://www.ncbi.nlm.nih.gov/pmc/articles/PMC4783473/pdf/cr20162a.pdf>. Acesso em: 24 ago. 2021

HEISS, B. L., MAXIMOVA, O. A., PLETNEV, A.G. Insertion of MicroRNA Targets into the Flavivirus Genome Alters Its Highly Neurovirulent Phenotype. Journal Of Virology. fev., 2011, v. 85, n. 4, p. 1464-1472. Disponível em: <https://www.ncbi.nlm.nih.gov/pmc/articles/PMC3028900/pdf/2091-10.pdf.>. Acesso em: 24 ago. 2021.

HOLANDA, G. M. Associação da expressão de proteínas-chave da biogênese dos microRNAs, citocinas e apoptose em linhagem celulares de hepatocarcinoma humano experimentalmente infectadas com o vírus da Febre Amarela. 2017. 74 p. Tese (Doutorado em Virologia) - Instituto Evandro Chagas, Ananindeua, 2017. Disponível em: <https://patua.iec.gov.br/bitstream/handle/iec/3072/Associa\%C3\%A7\%C3\%A3o\%20da $\% 20$ express $\%$ C3\%A3o\%20de\%20prote\%C3\%ADnas-

chave $\% 20 \mathrm{da} \% 20 \mathrm{biog} \% \mathrm{C} 3 \%$ AAnese $\% 20 \mathrm{dos} \% 20$ micrornas $\% 2 \mathrm{C} \% 20$ citocinas $\% 20 \mathrm{e} \% 20$ apoptose $\% 20 \mathrm{em} \% 20$ linhagens $\% 20$ celulares $\% 20 \mathrm{de} \% 20$ hepatocarcinoma $\% 20$ humano $\%$ 
20experimentalmente $\% 20$ infectadas $\% 20$ com $\% 20 \mathrm{o} \% 20 \mathrm{v} \% \mathrm{C} 3 \%$ ADrus $\% 20 \mathrm{da} \% 20 \mathrm{Febre}$ \%20Amarela.pdf?sequence=1\&isAllowed=y>. Acesso em: 26 ago. 2021.

KAWAHARA, H., IMAI, T., OKANO, H., MicroRNAs in neural stem cells and neurogenesis. Front. Neurosci., 2012, v. 6, n. 30. Disponível em: <https://www.ncbi.nlm.nih.gov/pmc/articles/PMC3298868/pdf/fnins-06-00030.pdf>. Acesso em: 26 ago. 2021.

KOZAK, R. A. et al. MicroRNA and mRNA Dysregulation in Astrocytes Infected with Zika Virus. Viruses.14 out. 2017, v. 9, n. 10, p. 297. Disponível em: <https://www.mdpi.com/1999-4915/9/10/297>. Acesso em: 26 ago. 2021.

KRICHEVSKY, A. M. et al. Specific microRNAs modulate embryonic stem cell-derived neurogenesis. Stem Cells, 2006, v.24, p.857-864. Disponível em: < https://www.ncbi.nlm.nih.gov/pmc/articles/PMC2605651/pdf/nihms81626.pdf >. Acesso em: 24 ago. 2021.

LI, M. et al. MicroRNAs: Control and Loss of Control in Human Physiology and Disease. World J Surg. Texas, v. 33, n. 4, p. 667-684, abr. 2009. Disponível em: < https://www.ncbi.nlm.nih.gov/pmc/articles/PMC2933043/pdf/nihms227615.pdf.>. Acesso em: 26 ago. 2021.

LI, N., et al. microRNAs: important regulators of stem cells. Stem Cell Research \& Therapy. 2017, v. 8, n. 110. Disponível em: <https://www.ncbi.nlm.nih.gov/pmc/articles/PMC5426004/pdf/13287_2017_Article_55 1.pdf. $>$. Acesso em: 25ago. 2021.

LIU, C., ZHAO, X., MicroRNAs in Adult and Embryonic Neurogenesis. Neuromolecular Med. 2009, v. 11, n.3, p. 141-152. Disponível em: <https://www.ncbi.nlm.nih.gov/pmc/articles/PMC2754598/pdf/nihms138894.pdf>.

Acesso em: 26 ago. 2021.

MAKEYEV, E. V. et al. The MicroRNA miR-124 Promotes Neuronal Differentiation by Triggering Brain-Specific Alternative Pre-mRNA Splicing. Mol Cell. 3 ago. 2007. v. 27 , n. 3, p. 435-448. Disponível em: <https://www.ncbi.nlm.nih.gov/pmc/articles/PMC3139456/pdf/nihms306723.pdf>.

Acesso em: 24 ago. 2021.

MINER, J. J., DIAMOND, M. S. Zika Virus Pathogenesis and Tissue Tropism.Cell Host \& Microbe. Saint Louis, 8 fev 2017, v. 21, p. 134-142. Disponível em: <https://www.ncbi.nlm.nih.gov/pmc/articles/PMC5328190/>. Acesso em: 24 ago. 2021.

NELSON, P. T., WANG, W. X., REJEEV, B., MicroRNAs (miRNAs) in Neurodegenerative Diseases. Brain Pathol. 2008, jan., v. 18, n. 1, p. 130-138. Disponível em: <https://www.ncbi.nlm.nih.gov/pmc/articles/PMC2859437/pdf/nihms180033.pdf>. Acesso em: 26 ago. 2021.

OLIVEIRA, L. F. de. Perfil de microRNAs Hepáticos pode Regular Apoptose, Lesões Vasculares e Inflamação na Dengue Hemorrágica. 2016. 122 p. Tese (Doutorado em 
Genética e Biologia Molecular) - Universidade Federal do Pará, Pará, 2016. Disponível em: < http://repositorio.ufpa.br/jspui/bitstream/2011/8882/1/Tese_PerfilMicroRna.pdf >. Acesso em: 26 ago. 2021.

ROSA, A., BRIVANLOU, A. H., Regulatory Non-Coding RNAs in Pluripotent Stem Cells. International Journal of Molecular Sciences. 2013, v. 14, p. 14346-14373. Disponível em: <https://www.ncbi.nlm.nih.gov/pmc/articles/PMC3742248/pdf/ijms-1414346.pdf. >. Acesso em: 25 ago. 2021.

SHIM, J., NAM, J. W., The expression and functional roles of microRNAs in stem cell differentiation. BMB Reports, 2016, v. 49, n. 1, p. 3-10. Disponível em:<https://www.ncbi.nlm.nih.gov/pmc/articles/PMC4914210/pdf/BMB-49-3.pdf>.

Acesso em: 25 ago. 2021.

SILVA, A. B. R. da. Aspectos gerais da infecção pelo vírus Zika: uma revisão. 2017. 73 p. Monografia (Graduação em Biomedicina) - Universidade Federal do Rio Grande do Norte, Rio Grande do Norte, 2017. Disponível em: < https://monografias.ufrn.br/jspui/handle/123456789/5553>. Acesso em: 25 ago. 2021.

SILVA, E. et al. Zika Vírus: Fatores Evolutivos Determinantes para a sua Epidemia e Patogenia. Revista Saúde Integrada, Faculdade CNEC Santo Ângelo, v. 10, n. 19, p. 51-59, 2017. Disponível em: < http://local.cnecsan.edu.br/revista/index.php/saude/article/view/481.>. Acesso em: 25 ago. 2021.

SONG B. H. et al. Zika virus: History, epidemiology, transmission, and clinical presentation. Journal of Neuroimmunology. v. 308, p. 50-64, 2017. Disponível em: < https://www.jni-journal.com/article/S0165-5728(16)30483-0/fulltext.>. Acesso em: 26 ago. 2021.

SULLIVAN, C. S., GANEM, D. MicroRNAs and viral infection. Molecular cell. 7 out. 2005, v. 20, n.1, p. 3-7. Disponível em: <https://pubmed.ncbi.nlm.nih.gov/16209940/>. Acesso em: 25 ago. 2021.

TETERINA, N. L., et al. Silencing of neurotropic flavivirus replication in the central nervous system by combining multiple microRNA target insertions in two distinct viral genome regions. Virology. 2014, v. 0, p. 247-258. Disponível em: <https://www.ncbi.nlm.nih.gov/pmc/articles/PMC4075184/pdf/nihms584436.pdf>. Acesso em: 25 ago. 2021.

TISCORNIA, G., BELMONTE, J. C. I. MicroRNAs in embryonic stem cell function and fate. Genes \& Development. 2010, v. 24, p. 2732-2741. Disponível em: <https://www.ncbi.nlm.nih.gov/pmc/articles/PMC3003189/pdf/2732.pdf.>. Acesso em: 26 ago. 2021.

VISVANATHAN, J., The microRNA miR-124 antagonizes the anti-neural REST/SCP1 pathway during embryonic CNS development. GENES \& DEVELOPMENT, 2007, v. 21, p. 744-749. Disponível em: <https://www.ncbi.nlm.nih.gov/pmc/articles/PMC1838526/pdf/744.pdf>. Acesso em: 25 ago. 2021. 
YOO, A. S. et al. MicroRNA-mediated switching of chromatin-remodelling complexes in neural development. Nature. 30 jul. 2009, v. 460, n. 7255, p. 642-646.Disponível em: <https://www.ncbi.nlm.nih.gov/pmc/articles/PMC2921580/pdf/nihms214891.pdf>.

Acesso em: 24 ago. 2021.

YUAN, K. et al. The miR-290-295 cluster as multi-faceted players in mouse embryonic stem cells. Cell \& Bioscience. 2017, v. 7, n. 38. Disponível em: $<$ https://cellandbioscience.biomedcentral.com/articles/10.1186/s13578-017-0166-2>. Acesso em: 25 ago. 2021.

ZHAO, C., et al. MicroRNA let-7d regulates the TLX/microRNA-9 cascade to control neural cell fate and neurogenesis. Scientific Reports. 2013, v. 3, n. 1329, p. 1-7. Disponível em: <https://www.ncbi.nlm.nih.gov/pmc/articles/PMC3580325/pdf/srep01329.pdf>. Acesso em: 24 ago. 2021.

\section{Recebido em: 01/09/2021}

Aprovado em: 12/09/2021

Publicado em: 16/09/2021 